\title{
Ethical Considerations in Conducting Research with Non-native Speakers of English
}

\author{
Joanna Koulouriotis
}

The ethical considerations of three education researchers working with nonnative English-speaking participants were examined from a critical theory standpoint in the light of the literature on research ethics in various disciplines. Qualitative inquiry and data analysis were used to identify key themes, which centered around honor and respect for participants' voices and the researchers' perceived limitations of university research ethics boards (REBS) to address adequately their concerns when working with non-native English speakers.

Nous avons examiné, sous l'optique de la théorie du criticisme et à la lumière de la littérature sur l'éthique en recherche dans diverses disciplines, les considérations déontologiques touchant la recherche de trois chercheurs en éducation qui travaillent avec des participants dont la langue maternelle n'est pas l'anglais. Une enquête qualitative et une analyse des données ont servi dans l'identification des thèmes principaux, qui s'articulaient autour des idées d'honneur et de respect pour la voix des participants d'une part, et des limites que percevaient les chercheurs dans la possibilité pour les comités d'éthique de la recherche universitaire de traiter de façon adéquate les préoccupations des locuteurs dont la langue maternelle n'est pas l'anglais d'autre part.

\section{Introduction}

Over the last 30 years, research into English-as-a-second-language (ESL) acquisition and instruction has expanded exponentially. As comprehensive and varied as much of the research in ESL is, little of what has been written addresses the ethical considerations inherent in and raised by ESL research. In contrast, ethical considerations for research are being discussed in various other disciplines such as medicine and nursing (Edwards, Lilford, Thornton, \& Hewison, 1998; Turale, 2006), psychology and psychological counseling (Fisher, 2004; Stuart, 1998; West, 2002), Aboriginal studies (Ellis \& Earley, 2006; Piquemal, 2001), and anthropology (Gottlieb, 1997). By extension, therefore, it seems appropriate that ethical issues in ESL research should also be identified and examined, especially because much of the research in ESL is conducted by teacher-researchers and/or researchers in countries where ethical concerns may not be addressed formally or by encompassing human 
rights legislation. However, even in countries such as Canada where all universities have research ethics boards (REBs), it is important to investigate whether the ethics protocols laid out by university REBs adequately address the needs of researchers working with participants who are non-native speakers of English.

The purpose of this study was to investigate the ethical concerns of researchers in the education faculty at a Canadian Prairie university whose participants are frequently non-native speakers of English and to consider these concerns in the light of the REB protocols in this university. Specifically, this study aimed to determine what ESL researchers considered the most salient ethical issues when conducting research with participants for whom English is not a first language-such as international students, newcomers or immigrants to Canada, and Aboriginal people-and to explore how researchers address these issues. This study also sought to investigate whether researchers felt that the ethical requirements laid out by the REB at this university sufficiently addressed the needs and concerns of education researchers working with non-native English-speaking participants. My specific research question is: What are the main ethical concerns of researchers who conduct research with non-native speakers of English? Additional research questions include: How do researchers address these ethical concerns or issues in their own research? How sufficiently do REBs such as the education REB at this university address these concerns?

\section{Background/Conceptual Framework}

As comprehensive as much of the research in the field of ESL is, little in the literature addresses the nature of ESL research itself; specifically, little is being written on the ethical considerations inherent in and raised by ESL research. Although in Manitoba the term English as an Additional Language (EAL) is currently used to refer to students who are non-native speakers of English, I continue to use the term ESL in the parameters of this study as it is recognized both in Canada and internationally and has, therefore, broader conceptual uses. According to Gottlieb (1997), as we begin to "interrogate the foundations of the research endeavour, the more we discover that the issue is fraught with complexities" (p. 3). As Gottlieb suggests, it is not good enough to assume that all research, in this case, research with non-native speakers of English, is being conducted ethically, transparently, and unproblematically. Rather, by examining the beliefs and practices of researchers with non-native speakers of English, we can better understand the ethical issues involved.

To help pinpoint what the ethical considerations specific to research with non-native speakers of English might be, I briefly turn to a discussion of ethics in the larger domain of education research and across other disciplines. By no means exhaustive, this list includes issues of informed consent, the use 
of language, respect for participants' voices, the relationship between researcher and participant, and the role of REBs. First to be considered is the notion of informed consent, which requires that participants fully understand the nature of the research being conducted as well as their role in and contribution to the research. Their involvement must be free and voluntary, and they must understand that withdrawal from the research is possibly at any stage without penalty. Fisher (2004) outlines a set of criteria for establishing and maintaining informed consent, and although her guidelines pertain to clinical research involving children and adolescents, many of her suggestions are relevant to research involving non-native speakers of English. Of primary importance is that researchers "use language that is reasonably understandable to the learner" (p. 834). But researchers' responsibility to ensure that participants fully understand what their involvement in the research entails is not limited solely to the use of appropriate language. Non-native language speakers may for cultural reasons feel that they cannot refuse a request to take part in research because they may perceive the researcher as being in a position of authority. The participants' own culture(s) thus come into play. It is arrogant to assume that the culture of the researcher or the culture in which the research takes place must take precedence. In considering research with North American Aboriginal populations, Piquemal (2001) argues that researchers frequently assume that participants are "able to give full permission in a communicative code that happens to belong to the researcher" (p.165). So if the participant and the researcher belong to different cultures, it is possible that both ethics and the research process will mean something different to each. Participants who are non-native speakers of English sometimes come from cultures markedly different from those of researchers, so more may be needed on the part of the researcher to meet the participants' expectations.

Thus when considering ethical issues in research with non-native speakers of English, the role of the researcher needs to be considered. In discussing ethical issues in the field of anthropology, Gottlieb (1997) argues that "researchers, as human beings, are continually subject to emotional reactions to their research, and such reactions must be interrogated if the research endeavour is to be understood" (p. 8). Researchers' emotions and values shape their research decisions, and if how this happens goes unquestioned, ethical concerns may be raised. Research is never value-free, and to assume that it is can be problematic. Researchers must position themselves in their work; they have an ethical responsibility to be up front about their values, beliefs, and biases in order to make research with non-native speakers of English more accountable.

In discussing accountability, it is natural to consider university REBs. But is satisfying REBs all that is ethically needed on the part of the researcher? Davison, Brown, and Moffat (2006) explore this question in their discussion of student researchers' experiences navigating through research review boards. In a study involving novice researchers working with northern Abo- 
riginal communities, the writers found that new researchers encountered many difficulties in negotiating the sometimes conflicting agendas of university REBs and those of the communities in which they were conducting their research. They concluded that "ethics review should ... not exist as a procedural hurdle that is distanced from the reality of the research experience" (p. 9). In discussing research in nursing, Stuart (1998) is more critical in her appraisal of REBs, asserting that they "are designed to protect the researcher and the institution from lawsuits" (p. 305). Such concerns are magnified when the research is conducted with non-native speakers of English who are probably unfamiliar with such institutions and who may feel alienated from the dominant culture.

In discussing ethical problems in research involving children, Thomas and O'Kane (1998) touch on the importance of allowing children "to participate on their own terms" (p. 338) and to have their voices heard throughout the research process. For Thomas and O'Kane, this involves giving children some choice as to how they will participate and some input into the research questions. Although these researchers are not working with non-native speakers of English, they are working with a vulnerable population. I do not wish to imply that participants who are non-native speakers of English should be treated the same as children, for this would be condescending, simplistic, and disrespectful; however, some lessons can be learned from research with children and youth. For West (2002), who explores the ethical practices of counseling and research, allowing participants' voices to be heard during the research process involves allowing participants some say in drafting and editing material intended for publication. When conducting research with non-native speakers of English, similar considerations can be made to recognize, respect, and include participants' voices.

In this article, I adopt a critical theory standpoint. According to Bogdan and Knopp Biklen (2007), critical theory "is critical of social organizations that privilege some at the expense of others" (p. 22). Critical theorists, therefore, seek to locate and identify how social organizations create and perpetuate the marginalization of some groups in society, eventually striving for a transformation of existing institutions. Researchers have a certain degree of power in that they are educated and privileged and frequently work in universities, which are powerful social institutions. Moreover, considerable disparity can exist between researchers and their non-native English-speaking participants. By the nature of their work, researchers have the power to question and challenge or validate and uphold the power balances that they perceive among the populations with which they come into contact. Therefore, critical theory is a fitting means for examining the ethical considerations of researchers who work with non-native English-speakers. However, as a novice researcher myself, I am mindful of the need to avoid being overzealous in my analysis of the concerns and issues that my participants, the education researchers, have 
raised in my study. The purpose of this article is to present and discuss these ethical concerns and the extent to which researchers believe that these concerns are addressed by university research ethics boards.

\section{Method}

This study is qualitative in nature because the research questions are subjective and depend on the context, philosophy, and experiences of those participating in the study. Three researchers from the education faculty in a Canadian Prairie university who frequently conduct research with nonnative English-speaking participants were interviewed during October and November 2008. As this research was a pilot study, the number of participants was limited to three; despite this being a pilot study, ethical review approval was sought and received. Because of the specified knowledge expected of the participants, purposeful sampling was used. The subject pool was small because the research was directed only at faculty members conducting research with non-native speakers of English. By accessing university Web sites (in order to find out about faculty members' research interests) and by working with my faculty advisor, I compiled a list of potential participants. I contacted each by e-mail, informing them of the nature of the study and inviting them to participate. Three female education researchers agreed to take part in the study.

Each individual interview took approximately one hour to complete. Participants were asked about their research interests, their experiences of doing research with non-native speakers of English, their experiences in getting research projects approved by REBs, and any considerations they typically took into account when conducting research with non-native speakers of English. I audio-recorded the interviews and later transcribed them verbatim. I provided all participants with a copy of the transcripts of their interviews and gave them the opportunity to member-check the transcripts. Participants were assigned pseudonyms (one participant chose her own), and identifying markers were removed from the data.

Following qualitative research guidelines, the data from the interviews were then analyzed. In order to identify themes in the data, the interview transcripts were coded and categorized into meaningful units of data. Similarities and differences were determined through a careful comparison of the transcripts, and these are presented in the findings below.

\section{Findings}

I asked education researchers Danielle Doyle, Yu-Lan Bai, and Krista Granby to reflect on the their issues and concerns when conducting research with non-native speakers of English and the subsequent decisions that these considerations have led them to make. In the light of these issues, I asked them 
to consider their experiences of having research applications approved by REBs and to assess how well REBs addressed their ethical concerns. Their reflections are given below.

\section{Ethical Considerations}

Informed consent. Each of the participants in this study highlighted several ethical issues that they took into account when conducting research with non-native speakers of English. All three spoke to various degrees about the concept of informed consent. Researchers emphasized the importance of ensuring that their participants understood fully and freely gave their consent to take part in a given research study, but they expressed concerns about how best to realize this consent. One researcher spoke of the awkwardness she felt, as a novice researcher in getting her participants, who were international students studying in Canada, to sign a consent form for her first research project in North America:

I need to get their consent ... informed consent ... and get them to sign [a consent form]. I asked them and they already agreed orally, but in the North American context, that doesn't count. You have to have documentation. So I just felt ... not very comfortable because that's not what we do ... in my home country. (Interviewee 2)

Another researcher also touched on the cultural challenges surrounding informed consent when she stated that one of her concerns was "whether or not [her] understanding of research ethics and [the participant's] understanding of ethics are the same, and if they are the same, what forms of consent are appropriate?" (Interviewee 1)

She further questioned, "What if the whole issue of consent is just abhorrent to [the participant's] community?" She felt that consent itself was a Western construct and that the notion of consent was a means of colonization. Another researcher expressed concerns that participants might be "giving consent that is genuine but is not totally always informed" (Interviewee 3).

Comments such as these suggest that researchers have difficulty in conceptualizing informed consent such that consent will be meaningful for their participants. This difficulty may be a product of the disparity between participants' culture(s) and that of the researcher. For example, one researcher emphasized the need for "an informed type of consultation that ... is key for cross-cultural work or work with non-native speakers of English" (Interviewee 3). Another suggested that consent "should be an ongoing thing [that's] not done just once at the beginning of a research relationship" (Interviewee 2). In a similar vein, one researcher argued that:

Ethics really involves the relationship and it's not because you have a signature that you can think it's done. It only begins then. (Interviewee 3) 
Another researcher took issue with the idea of a consent form as a means of ensuring consent, arguing that "some stupid little piece of paper with their signature is not going to protect [the participants]" (Interviewee 1). How consent is realized or obtained was clearly problematic for the researchers. It would seem, however, that consent for these researchers was far from a simple concept, but rather one that must be considered in the light of participants' own culture(s) and values.

Language and translation. Two related concerns of all three researchers involve the issues of language and translation. Although each of the researchers spoke about language and translation, the degree of importance for each differed, and there was no consensus among them on how best to address these issues. One argued that it was difficult to access fully the experience of a participant who was a non-native speaker of English by using English during the research interview. She commented:

Sometimes I find it hard to translate an experience in one language to another ... Actually, one of my participants ... said that you [lose] something in translation when you translate one experience in one language to another language. (Interviewee 2)

Another researcher mirrored these sentiments when she spoke about working with a translator during an interview with an Aboriginal elder:

I get this translation and I can just tell ... particularly, with Aboriginal people, their worldview is so different ... I am aware that there are things that are lost in translation. (Interviewee 3)

Another researcher, on the other hand, avoided the use of translators in the Canadian context altogether because she felt that it was "impossible to come up with an exact translation" (Interviewee 1). In admitting that conducting interviews in English with non-native speakers can sometimes take considerably longer because of the need to clarify and explain a great deal more, she argued, "And what's it to me if it takes three hours to get through what might have taken one hour? What's it to me? If I can't give my time back to people, what use am I?"

Moreover, during one particular research study, she discovered that by conducting the research in English she was helping the participants to realize their ability to make themselves understood beyond their grammar or pronunciation. Although she admitted that conducting interviews in English required intensive listening and much work on the part of the researcher, she was surprised to learn that through participating in research, participants felt a sense of pride and accomplishment. She found that in her work with immigrants in a Canadian context, her participants were grateful for the opportunity to be heard in English in "an authentic communication context." 
In contrast, another researcher often conducted interviews in the participant's native language and would then translate them into English because she believed that "deep down in terms of what [the participants] really feel, what they really think, only their mother tongue can help them and me ... access that deeper level of experience" (Interviewee 2). For this researcher, the understanding of how the participant's language competence could sometimes help or hinder his or her ability to access experience was key. Although the researchers did not agree on which language should be used during the research process or on the use of translation, they did share a similar desire to honor their participants' experiences, whatever individual language choices they made as researchers.

Positionality. Each of the researchers spoke about the positionality of the researcher to some extent. Researchers spoke primarily about the relationship between the researcher and the participant, but they were also interested in the role of the researcher in the research and the researcher's world view and how these factors might influence the research. Each researcher emphasized the need to be up front about her own positionality when doing research; that is, each felt that the researcher must be clear about who she was and her relationship with the participants. As one researcher explained, "I don't believe in objectivity, in being removed" (Interviewee 3). In considering that the participants might come from varied cultures, this researcher believed:

They ... want to know who you [the researcher] are, what's your story, why you're there. That's part of the connecting ... They want to get a different sense of all the different layers in you ... the person behind the researcher. (Interviewee 3)

Still another researcher spoke about the nature of the researcher-participant relationship, stating that she was "really mindful" (Interviewee 2) and cognizant of how she as a researcher could influence her participants. She further pointed out that trust may develop between the researcher and the participant over time, particularly if the research extended over several months or years. However, one researcher cautioned that the researcher-participant relationship could sometimes become blurred, as is the case when participants confide in the researcher and perhaps treat the research process as therapy. This researcher recognized that there was potential to share private stories that were not meant to be "public research stories" (Interviewee 3) and that the onus was on the researcher not to take advantage of the trust or friendship that might develop between researcher and participant. One researcher summed up well the sentiments of all three about the role of the researcher vis-à-vis the participants:

So it's this constant ... monitor of what I do as a researcher and what impact I might have on my participants. And so, for me, I think re- 
search ethics is a relational ethic and my relationship with my research participants is the most important factor for me to think about. (Interviewee 2)

This suggests that the researcher is not an objective entity somehow removed from the research endeavor, which is supported by researchers' recognition of their relationship with the research process itself. One researcher stressed her need "to take the time and opportunity to locate [herself] in the research so it's really clear ... what [her] own ideological position is" (Interviewee 1). Another acknowledged in her writing her "inability to comprehend holistically" (Interviewee 3) when there was a language barrier, for example. These comments suggest that researchers need to be continually aware of and honest about their place in the research. Researchers influence the research process, and although such influence may never be completely negated, it does need to be acknowledged.

Voice. In discussing ethical considerations such as informed consent, language and translation, and the researcher's positionality, researchers often touched on the need to honor and respect participants' voices. One researcher encouraged participants to use photographs or drawings to help them access their experiences because "sometimes their language proficiency will prevent them from sharing their whole experience" (Interviewee 2). This suggests that language considerations are based on a need to respect and help give voice to participants' experiences. All the researchers were adamant about the need to listen to participants so that they would feel that their experiences and opinions were valued. By establishing a good researcher-participant relationship, one researcher felt that her participants knew that she was "there to listen" (Interviewee 2), to understand their experiences, and to help them "find their voice." Another researcher emphasized the importance of member checks in order to ensure that participants could help shape the experiences that they shared and to ensure that their voices were authentic.

Moreover, researchers spoke of the empowerment that participants often felt once they believed that their voices were being heard and honored. One spoke of the pride and accomplishment participants felt after listening to their taped interview or after reading the transcript, knowing that they were able to communicate and be understood. Another researcher was touched to receive thank-you letters from her participants after she had given them the respective sections from her dissemination of the findings in which their experiences were written. The participants thanked her for "being a listener and offering them a space" (Interviewee 2) where they could think about and tell of their experiences. Before making her own formal analysis of interviews with participants, another researcher not only encouraged her participants to share their stories, but also gave them the opportunity to make sense of their own experiences, which therefore "gives them that additional layer of 
voice" (Interviewee 3). These comments suggest that allowing participants who are non-native speakers of English the opportunity to share their voices helps participants gain empowerment and validation in new ways.

\section{Working with Research Ethics Boards (REBS)}

The researchers' responses to questions about the role of university REBs in how they conduct research with non-native speakers of English were varied. One researcher argued that the purpose of this university's REBs was "a policing function" (Interviewee 1). She had served on an REB and regretted that it was necessary for REBs to have a policing function because abuses had taken place in the past. She also felt that the REB "discourages curiosity in different research" and was becoming "more and more litigiously concerned." She believed that "ethics review protocols are intended to defend the institution, not the participants." Another researcher was less critical about the role and function of this university's REB. She stated that the board was important for making researchers "aware of issues of confidentiality, privacy and power" (Interviewee 3). However, she also felt that the "attitude of the researcher is key." Moreover, she added that she was sometimes tempted to change her research methodology just "so they'll let [her] through." She felt that this REB was trying to become more inclusive, but ultimately, it was her responsibility as a researcher to adhere to what she believed in and knew to be ethically fair "without compromising" her own integrity as a researcher. In conducting research with Aboriginal populations, for example, she had conducted some interviews in participants' homes, and she and her participants had begun "by visiting" first. This dimension of personal connection was not something that the REB recognized as critical for research with some groups of non-native speakers of English. Another researcher, who had had experience in getting ethics approval for her research projects at diverse universities, believed that the protocols were simply "only a first step" for researchers (Interviewee 2). She felt that:

The ethics review board [hasn't] really paid ... attention to this group of potential research participants, and now I think it kind of almost leaves it to the individual researcher to make ethical decisions about how they conduct this kind of research with non-native speakers of English.

Although the three researchers regarded the process of gaining ethical approval by REBs somewhat variably, they all seemed to believe that gaining ethics approval was simply one step in the process and that the responsibility to be ethical ultimately rested on the researchers' shoulders.

In reflecting on the ethics protocols, all the researchers touched on the potential disparity between how REBs conceptualized ethical research conduct and how ethics and the research endeavor were perceived in participants' 
own cultures. One researcher pointed out, "research is a Western institutiondriven phenomenon" (Interviewee 1), so a key consideration of hers was "whether or not [her] understanding of ethics is the same [as her participants']." Another worried that participants' potential lack of understanding about how research plays out in Canada might result in participants being "manipulated" (Interviewee 2). For her, this was not simply because of language differences, but because of "cultural aspects." Therefore, she felt it was important for REBs to think about establishing some guidelines for researchers conducting research with non-native speakers of English. One researcher also felt a need for "an official guideline for that informed type of consultation that ... is key for cross-cultural work or work with non-native speakers of English" (Interviewee 3). Another expressed concerns that participants might agree to take part in a research project in order to be "helpful" and to give the researcher "the answer that [she wants] because research is a very new or even strange idea" (Interviewee 2) for some participants from diverse cultural backgrounds. These observations suggest that researchers believe that university REBs should be mindful of the fact that participants may come from cultures where research and ethics are realized in other ways than in Canada.

\section{Discussion}

During the interviews with researchers who work with non-native speakers of English, some large issues were raised that center around honoring and respecting participants' voices as well as the limitations of REBS.

\section{Participants' Voices}

Whether considering informed consent, language and translation, or the relationship between researcher, participant, and the research process, the education researchers interviewed for this study were concerned about the need to allow participants' voices to be heard and to honor and respect the experiences of participants who are non-native speakers of English. In considering informed consent, the researchers agreed that participants needed to be informed about the research process, but they did not agree on how to put consent into practice or whether the very notion of consent was acceptable. Their varied perspectives on consent might have been shaped in part by the specific groups of participants with which they frequently conducted research. Although each worked with non-native speakers of English, there are some differences between Aboriginal people, international students, and immigrants, for example. To cluster all groups of non-native English speakers together in the same group may be problematic. However, the purpose of the current study was to look at this larger grouping as it represented similar challenges, concerns, and needs that were different from those of participants belonging to the dominant group and speaking the dominant language in 
society. Moreover, this grouping of participants into non-native speakers of English has yielded some significant findings. For example, researchers wish to address informed consent so as to respect participants' own beliefs and cultures. Marshall and Batten (2004) argue that we must not attempt "to adhere to any universal ethic in designing and conducting research [but] respect the ... ethical norms of a given cultural or ethic group" (p. 4). One researcher's challenge to the idea of consent and the use of consent forms stemmed from her desire to respect the rights of her participants and her fear that consent itself implied "subjugation" and "issues of power" (Interviewee 1). This researcher wished to allow participants to speak and be heard, but not at the expense of their power. The other two researchers spoke more about the ongoing nature of consent insofar as non-native English-speaking participants must continually be given the opportunity to voice any concerns or doubts that they may have about the research project. Marshall and Batten (2004) argue that "the source of consent for participants from cultural or ethical groups must be more clearly and operationally defined than for mainstream groups" (p. 2). It is this constant redefinition that the researchers interviewed for this study were trying to achieve and in so doing respecting the voices of their participants.

Although the researchers did not agree on whether to conduct research in participants' own languages and use translators, each was striving to represent best participants' experiences. Indeed, Davison et al. (2006) found that translating into participants" own native languages might not guarantee "that the level of understanding or respect will be increased" (p. 6). It may be that a concept simply exists outside a participant's own culture. Two of the researchers mentioned that participants might begin to see themselves in a new light after they had successfully made themselves heard in English, and this process could be transformative. Set against this was the real danger of participants' difficulty in fully accessing their experiences and stories. Irrespective of whether the researcher chooses to use translation, each is committed to facilitating the authentic voices of their participants.

Stuart (1998) argues that research does not involve a simple, accurate rendering of participants' experiences; rather, the meaning of a participant's experience is changed once "a researcher joins that person to explore the experience" (p. 309). Stuart believes that "the process of exploration" itself changes the experience. This possibility is something that researchers seem to be aware of as each finds it important either to consult continually with participants throughout the process and/or provide the participants with opportunities to member-check their words to see if they represent what they truly feel. So it is not surprising that researchers acknowledge their own positionality vis-à-vis participants and the research itself. Researchers recognize that they do not stand outside the research process, and by virtue of the choices they make and the role they play for participants, they must be care- 
ful not to influence unduly the voice of participants. Research with non-native speakers of English, a group that may not have much social clout or power in the larger dominant society, is important because otherwise, "their story, their experience won't be heard" (Interviewee 2).

\section{Limitations of REBs}

It is somewhat ironic that institutions established specifically to ensure that research involving human participants is conducted ethically should prove problematic in terms of the ethical considerations of researchers working with non-native speakers of English. There was a noticeable difference in the degree to which each researcher was critical of university REBs, but this may be attributable either to the researchers' own experiences in submitting research applications for approval or to their own personal orientation toward research, participants, and the research process. The institutional contexts in which the researchers work must also be considered. Although REBS from diverse Canadian universities arguably serve the same function, the reality of submitting research projects for ethics approval may differ considerably from one institution to another, thereby influencing researchers' response to REBs in general. Nevertheless, it appears that all the researchers relied primarily on their own ethical compass or understanding of how best to address any of the ethical considerations explored in this article.

\section{Conclusion}

Although the literature in the field of ESL offers little discussion of the ethical concerns of researchers working with non-native speakers of English, the results of this study suggest that this is a salient topic ripe for discussion. The findings from this study suggest that education researchers are concerned with the issue of informed consent. Two researchers were concerned with how best to conceptualize consent and then obtain informed consent so that it is meaningful for participants, whereas the third researcher expressed concerns about the nature of consent, seeing it as means of subjugation. Researchers were also mindful of the use of language, whether English or the participants' own language, and whether to use translation as an effective means of accessing participants' experiences and beliefs. Researchers were also concerned with the relationship between themselves and their participants and the research endeavor, and how participants' own understanding of both the research process and research ethics must be taken into account, especially when conducting research with non-native speakers of English for whom cultural norms and expectations may be significantly different from those of the dominant culture. Underlying all these concerns was researchers' primary desire to honor and respect and to give an outlet to participants' voices. In considering the ethics protocols laid out by REBs, researchers worked with their universities' REBs but found some limitations. For re- 
searchers working with non-native English-speaking participants, the ethics protocols might be a starting point; researchers continually scrutinize their own practices, acknowledging that ethics are the responsibility of the individual researcher and that ethical conduct is a continual, ongoing process.

The issues raised by this study are not likely to be easily or neatly resolved soon, and my purpose here is not to prescribe a series of guidelines for researchers to follow. Indeed, in considering my own position regarding ethics in research with non-native speakers of English, I find that my understanding is transforming and adapting. It is easy for me to be critical in my desire to see more discussion of ethics in research, but I must acknowledge my own lack of practical research experience. So instead, this current study simply highlights some ways that ethics play a significant role in research with nonnative speakers of English and, I hope, provides an opportunity for researchers' reflection and discussion. Further study on the specific needs of participants who do not speak the dominant language or belong to the dominant cultural group in society is called for. In addition, research comparing the concerns of non-native and native English-speaking participants would further illuminate the concerns of researchers and their participants, and by extension those that REBs need to consider. I hope that by conducting these kinds of studies, research with non-native speakers of English both in and outside the ESL field can be advanced. Hostetler (2005) asserts, "our ultimate aim as researchers and educators is to serve people's well-being" (p. 16), and by giving serious thought to the ethical concerns and issues pertaining to research with non-native speakers of English, we can help ensure that our participants' voices are heard.

\section{The Author}

Joanna Koulouriotis has taught ESL/EAL both in Canada and abroad. She has recently received a master's degree in education, specializing in second-language education, from the University of Manitoba. She currently teaches in and develops curriculum for the Intensive English Program at the University of Manitoba.

\section{References}

Bogdan, R.C., \& Biklen, K.S. (2007). Qualitative research for education: An introduction to theories and methods (5th ed.) Boston, MA: Pearson, Allyn \& Bacon.

Davison, C.M., Brown, M., \& Moffit, P. (2006). Student researchers negotiating consent in Northern Aboriginal communities. International Journal of Qualitative Methods, 5(2), 1-10.

Edwards, S.J.L., Lilford, R.J., Thornton, J., \& Hewison, J. (1998). Informed consent for clinical trials: In search of the "best' method. Social Science and Medicine, 47(11), 1825-1840.

Ellis, J.B., \& Earley, M.A. (2006). Reciprocity and constructions of informed consent: Researching with Indigenous populations. International Journal of Qualitative Methods, 5(4), $1-9$.

Fisher, C.B. (2004). Informed consent and clinical research involving children and adolescents: Implications of the revised APA ethics code and HIPAA. Journal of Clinical Child and Adolescent Psychology, 33(4), 832-839.

Gottlieb, A. (1997). Comments on ethical issues in qualitative research. Paper presented at the annual meeting of the American Educational Research Association, Chicago. 
Hostetler, K. (2005). What is "good" education research? Education Research, 34(6), 16-21.

Marshall, A., \& Batten, S. (2004). Researching across culture: Issues of ethics and power. Forum: Qualitative Social Research, 5(3). Retrieved January 25, 2008, from: http://www.qualitative-research.net/fqs

Piquemal, N. (2001). Free and informed consent in research involving Native American communities. American Indian Culture and Research Journal, 25(1), 65-79.

Stuart, C.A. (1998). Care and concern: An ethical journey in participatory action research. Canadian Journal of Counselling, 32, 298-314.

Thomas, N., \& O'Kane, C. (1998). The ethics of participatory research with children. Children and Society, 12, 336-348.

Turale, S. (2006). Reflections on the ethics involved in international research. Nursing and Health Sciences, 8, 131-132.

West, W. (2002). Some ethical dilemmas in counselling and counselling research. British Journal of Guidance and Counselling, 30, 261-268. 